\title{
Dependence of century-scale projections of the Greenland ice sheet on its thermal regime
}

\author{
H. SEROUSSI, ${ }^{1}$ M. MORLIGHEM, ${ }^{2}$ E. RIGNOT, ${ }^{2,1}$ A. KHAZENDAR, ${ }^{1}$ E. LAROUR, ${ }^{1}$ \\ J. MOUGINOT ${ }^{2}$
}

\author{
${ }^{1}$ Jet Propulsion Laboratory, California Institute of Technology, Pasadena, CA, USA \\ E-mail: helene.seroussi@jpl.nasa.gov \\ ${ }^{2}$ Department of Earth System Science, University of California, Irvine, Irvine, CA, USA
}

\begin{abstract}
Observations show that the Greenland ice sheet has been losing mass at an increasing rate over the past few decades, which makes it a major contributor to sea-level rise. Here we use a threedimensional higher-order ice-flow model, adaptive mesh refinement and inverse methods to accurately reproduce the present-day ice flow of the Greenland ice sheet. We investigate the effect of the ice thermal regime on (1) basal sliding inversion and (2) projections over the next 100 years. We show that steady-state temperatures based on present-day conditions allow a reasonable representation of the thermal regime and that both basal conditions and century-scale projections are weakly sensitive to small changes in the initial temperature field, compared with changes in atmospheric conditions or basal sliding. We conclude that although more englacial temperature measurements should be acquired to validate the models, and a better estimation of geothermal heat flux is needed, it is reasonable to use steady-state temperature profiles for short-term projections, as external forcings remain the main drivers of the changes occurring in Greenland.
\end{abstract}

\section{INTRODUCTION}

Recent observations show an accelerated ice loss of the Greenland ice sheet (Velicogna, 2009; Rignot and others, 2011) during the past few decades, attributed to both changes in surface mass balance and ice dynamics (Howat and others, 2007; Rignot and others, 2011). Retreat of outlet glaciers is observed all around the periphery of the Greenland ice sheet; however, the acceleration has a high temporal and spatial variability (McFadden and others, 2011; Moon and others, 2012). Potential triggering mechanisms include, among others, increased calving rate (Benn and others, 2007), intrusion of warm water in the fjords (Holland and others, 2008), enhanced basal lubrication (Schoof, 2010) and cryo-hydrologic warming of ice (Phillips and others, 2010).

To better understand the behavior of the Greenland ice sheet, several large-scale ice-flow numerical models have been employed to simulate the evolution of the ice sheet over the coming centuries (Greve, 1997a; Ritz and others, 2001; Greve and others, 2011; Gillet-Chaulet and others, 2012; Seddik and others, 2012). These models rely on different iceflow approximations, parameterizations of physical processes and initialization procedures. Most ice-flow models rely on simplified first-order approximations of the momentum balance equations, such as the shallow-ice approximation (SIA; Hutter, 1982), the shelfy-stream approximation (SSA; MacAyeal, 1989; Greve and others, 2011; Aschwanden and others, 2012a) or a combination of SIA and SSA (Bueler and Brown, 2009; Pollard and DeConto, 2009). Initialization of these numerical models generally consists of running paleoclimate spin-ups over at least the last glacial cycle, in order to obtain a suitable present-day configuration (Greve and others, 2011; Aschwanden and others, 2012a). With this method, long-term memory of the ice-sheet evolution is included in several model variables (e.g. ice temperature). The spatial resolution of these models usually varies between 5 and $40 \mathrm{~km}$, due to intrinsic limitations of SIA and computational requirements. Previous studies (Ritz and others, 2001; DeConto and Pollard, 2003; Pollard and DeConto, 2009; Applegate and others, 2012; Rogozhina and others, 2012) illustrated the ability of these simplified models to improve our understanding of ice-sheet paleoclimate, as well as to evaluate the effect of different model parameters.

One major shortcoming of these models is that they operate at a relatively coarse spatial resolution compared with the size of outlet glaciers that control the ice discharge, which affect the total ice-sheet mass balance. Moreover, these models fail to reproduce observed dynamical changes of Greenland outlet glaciers where the model assumptions break down and where glacier size is comparable to the model spatial resolution (Gillet-Chaulet and others, 2012).

In order to better simulate the ice dynamics, several nextgeneration numerical models have been developed (Price and others, 2011; Gillet-Chaulet and others, 2012; Larour and others, 2012a; Seddik and others, 2012). These models include improved three-dimensional (3-D) models (e.g. higher-order (HO; Blatter, 1995; Pattyn, 2003) and fullStokes (FS) models), and use anisotropic mesh refinement (Morlighem and others, 2010) to capture narrow outlet glaciers at the ice-sheet periphery. Contrary to SIA- or SSAbased models, $\mathrm{HO}$ and FS models are too computationally intensive to perform interglacial spin-ups. In order to perform realistic simulations and start from a suitable representation of present-day conditions, these models either rely on spinups of simpler models (Seddik and others, 2012) or use data assimilation to reproduce present-day conditions (Morlighem and others, 2010; Larour and others, 2012a). The first method captures past changes of the ice sheet, but leads to discrepancies between the thermal regime and the stress regime. Indeed, the spin-up model and the model that is used for future scenarios have different spatial resolutions and rely on different ice-flow approximations, leading to an initial 
shock that influences the results (Seddik and others, 2012). The stress regime, and therefore the viscous and basal heating, is not consistent with the initial temperature. The second method consists of using present-day geometry of the ice sheet (ice thickness, surface elevation, ice front position) and inferring unknown parameters (e.g. basal friction) to reproduce observed velocities with data assimilation (MacAyeal, 1993a; Morlighem and others, 2010). As this method relies solely on present-day conditions, past climate variability is not accounted for. Temperatures are recovered using a thermal steady state (Morlighem and others, 2010; Larour and others, 2012a), even though the ice is not in thermal equilibrium. The ice velocity and geometry computed using such a method are consistent with present-day observations; however, inconsistencies between velocity and thickness datasets lead to ice flux divergence anomalies and models start by artificially redistributing the glacier mass, not as a realistic projection but to reconcile the inconsistencies (Seroussi and others, 2011).

The ice-sheet thermal regime has a large effect on the ice flow, as it affects basal melting and therefore the sliding of ice over its bed, and it also controls ice deformation. Ice-sheet thermal modeling is difficult due to the uncertainties in basal heat flux (Greve, 2005). Few deep ice cores are available to validate the models (Alley and others, 1993; Dansgaard and others, 1993; Greenland Ice Core Project (GRIP) members, 1993; Meese and others, 1994; Dahl-Jensen and others, 1998; NorthGRIP members, 2004). These ice cores provide temperature measurements through the ice column, but only in slow-moving areas of the Greenland ice sheet, near ice divides. Initializing ice-flow models with an appropriate thermal regime therefore remains challenging, especially for $\mathrm{HO}$ or FS models that cannot run interglacial spin-ups.

Here we assess the effect of the initial thermal regime on century-scale simulations of the Greenland ice sheet. To address this question, we (1) compare steady-state modeled ice temperatures against measurements from three deep ice cores, (2) analyze the sensitivity of inferred properties at the ice/bedrock interface to changes in ice temperature, (3) assess the effect of initial temperatures on century-scale projections and (4) compare the ice mass changes due to different initial temperatures against those obtained by changing external forcings, such as basal sliding or atmospheric conditions. We conclude by discussing the influence of the method employed in calculating the thermal regime on century-scale projections of ice-sheet evolution.

\section{MODEL AND METHODS Model description}

To model the Greenland ice sheet, we use the ice-sheet system model (ISSM; Morlighem and others, 2010; Seroussi and others, 2011; Larour and others, 2012a), an open-source finite-element software that simulates the thermodynamics of ice sheets at continental scale. Here we summarize the main characteristics and equations of the models (a complete description is given by Larour and others, 2012a).

Ice is modeled as a viscous incompressible material. We use the 3-D HO model (Blatter, 1995; Pattyn, 2003) for the momentum balance equations. This model is derived from the FS model by making two assumptions: (1) the horizontal gradients of vertical velocities are negligible compared with vertical gradients of horizontal velocity and (2) bridging effects are negligible. This leads to a 3-D model where horizontal and vertical velocities are decoupled. The ice viscosity, $\mu$, is assumed to be isotropic and to follow Glen's flow law (Glen, 1955):

$$
\mu=\frac{B}{2 \dot{\varepsilon}_{\mathrm{e}}^{\frac{n-1}{n}}} \pm,
$$

where $\dot{\varepsilon}_{\mathrm{e}}$ is the effective strain rate, $n$ is Glen's law coefficient (taken as $n=3$ ) and $B$ is the ice hardness. $B$ is mainly temperature-dependent and we rely on the relationship provided by Cuffey and Paterson (2010, p. 75). The horizontal velocity is a solution of

$$
\begin{aligned}
& \nabla \cdot\left(2 \mu \dot{\varepsilon}_{1}\right)=\rho g \frac{\partial s}{\partial x^{\prime}} \\
& \nabla \cdot\left(2 \mu \dot{\varepsilon}_{2}\right)=\rho g \frac{\partial s}{\partial y^{\prime}}
\end{aligned}
$$

with

$$
\dot{\varepsilon}_{1}=\left[\begin{array}{c}
2 \frac{\partial u}{\partial x}+\frac{\partial v}{\partial y} \\
\frac{1}{2}\left(\frac{\partial u}{\partial y}+\frac{\partial v}{\partial x}\right) \\
\frac{\partial u}{\partial z}
\end{array}\right] \quad \dot{\varepsilon}_{2}=\left[\begin{array}{c}
\frac{1}{2}\left(\frac{\partial u}{\partial y}+\frac{\partial v}{\partial x}\right) \\
\frac{\partial u}{\partial x}+2 \frac{\partial v}{\partial y} \\
\frac{\partial v}{\partial z}
\end{array}\right]
$$

where $(u, v, w)$ are the three components of velocity in a Cartesian coordinate system $(x, y, z)$, with $z$ the vertical axis, $\rho$ is the ice density, $g$ is the norm of the acceleration due to gravity and $s$ is the ice upper surface elevation. Vertical velocity is recovered using the equation of incompressibility.

The basal friction follows a viscous law (Cuffey and Paterson, 2010); the basal condition between the ice and the underlying bedrock is

$$
\left(\boldsymbol{\sigma} \cdot \boldsymbol{n}+\alpha^{2} N \boldsymbol{v}\right)_{\|}=0
$$

where $\boldsymbol{\sigma}$ is the stress tensor, $\boldsymbol{n}$ is the outward-pointing normal vector at the base, $\alpha^{2}$ is the friction coefficient, $N$ is the effective pressure, $\boldsymbol{v}$ is the basal velocity and $(\cdot)_{\|}$is a projection operator on the tangent to the bedrock. Effective pressure is $N=\rho g h$, with $h$ the height of the ice sheet above hydrostatic equilibrium as a first-order approximation; a hydrological model would be necessary to obtain a better estimate of basal pressure. The effective pressure varies with time as the ice-sheet geometry evolves. Other boundary conditions include water pressure at the ice front and air pressure for land-terminating glaciers, non-penetrability of ice into the underlying bedrock at the ice/bedrock interface and a free surface at the ice/air interface.

The evolution of the surface elevation is dictated by mass conservation. The mass transport equation reads

$$
\frac{\partial H}{\partial t}=-\nabla \cdot(H \overline{\boldsymbol{v}})+\dot{M}_{\mathrm{s}}-\dot{M}_{\mathrm{b}}
$$

where $H$ is the ice thickness, $\overline{\boldsymbol{v}}$ is the depth-averaged horizontal velocity, $\dot{M}_{\mathrm{s}}$ is the surface mass balance and $\dot{M}_{\mathrm{b}}$ is the basal melting. This hyperbolic equation is stabilized using a streamline upwinding finite-element method (Brooks and Hughes, 1982).

For the thermal model, we use an enthalpy formulation (as described in Aschwanden and others, 2012b). This method allows both temperate and cold ice to be included in an energy-conserving framework easily, as there is no need to track the cold/temperate transition surface used in polythermal models (Greve, 1997a,b). The enthalpy 
equation valid for both cold and temperate ice is

$$
\begin{aligned}
& \rho\left(\frac{\partial E}{\partial t}+\boldsymbol{v} \cdot \nabla E\right)= \\
& \Phi+ \begin{cases}\nabla \cdot\left(\frac{K_{\mathrm{i}}}{C_{\mathrm{i}}} \nabla E\right) & \text { if } E<E_{\mathrm{s}} \\
\nabla \cdot\left(k \nabla T_{\mathrm{pmp}}+\frac{k_{0}}{L} \nabla E\right) & \text { if } E_{\mathrm{s}}<E<E_{\mathrm{l}}^{\prime}\end{cases}
\end{aligned}
$$

where $E$ is the enthalpy, $E_{\mathrm{s}}$ is the enthalpy of pure ice, $E_{\mathrm{l}}$ is the enthalpy of pure liquid water at the pressure-melting point, $T_{\mathrm{pmp}}, K_{\mathrm{i}}$ is the ice diffusivity coefficient, $C_{\mathrm{i}}$ is the ice heat capacity, $k=(1-\omega) k_{\mathrm{i}}+\omega k_{\mathrm{w}}$ is the mixture thermal conductivity (with $\omega$ the water fraction and $k_{\mathrm{i}}$ and $k_{\mathrm{w}}$ the thermal conductivity of pure ice and liquid water), $k_{0}$ is a small positive constant and $\Phi$ is the internal deformation heat. The case of pure water, where enthalpy is above the enthalpy of pure liquid water, $E_{1}$, is not considered here.

The temperature, $T$, and water fraction, $\omega$, are recovered as follows:

For cold ice, $E<E_{\mathrm{s}}$ :

$$
\begin{aligned}
T & =\frac{E-E_{\mathrm{s}}}{C_{\mathrm{i}}}+T_{\mathrm{pmp}} \\
\omega & =0 .
\end{aligned}
$$

For temperate ice, $E_{\mathrm{s}}<E<E_{1}$ :

$$
\begin{aligned}
T & =T_{\text {pmp }} \\
\omega & =\frac{E-E_{\mathrm{s}}}{L} .
\end{aligned}
$$

Contrary to the description of Aschwanden and others (2012b), our model does not include a layer of the Earth's lithosphere, so the geothermal heat flux is directly applied at the ice base; ice in contact with the bedrock is heated by geothermal and frictional heat flux (Larour and others, 2012a). Air temperature is imposed on the upper surface.

Data assimilation of surface velocities is used to infer the basal friction coefficient as we try to minimize the misfit between modeled and measured surface velocities. We define the following cost function, $\mathcal{J}$ :

$$
\begin{aligned}
\mathcal{J}(u, v, \alpha)= & \gamma_{1} \frac{1}{2} \int_{\Gamma_{\mathrm{s}}}\left(u-u_{\mathrm{obs}}\right)^{2}+\left(v-v_{\mathrm{obs}}\right)^{2} \mathrm{~d} \Gamma_{\mathrm{s}} \\
& +\gamma_{2} \frac{1}{2} \int_{\Gamma_{\mathrm{s}}} \ln \left(\frac{\sqrt{u^{2}+v^{2}}+\varepsilon}{\sqrt{u_{\mathrm{obs}}^{2}+v_{\mathrm{obs}}^{2}}+\varepsilon}\right)^{2} \mathrm{~d} \Gamma_{\mathrm{s}}, \\
& +\gamma_{\mathrm{t}} \frac{1}{2} \int_{\Gamma_{\mathrm{b}}} \nabla \alpha \cdot \nabla \alpha \mathrm{d} \Gamma_{\mathrm{b}}
\end{aligned}
$$

where $\Gamma_{\mathrm{s}}$ is the domain upper surface, $\Gamma_{\mathrm{b}}$ its lower surface, $\left(u_{\text {obs }}, v_{\text {obs }}\right)$ the observed horizontal velocity and $\varepsilon$ is a minimum velocity used to avoid singularities. The first two terms in this cost function are the $\mathcal{L}^{2}$ misfit, which measures the square of the difference between model and observations, and the square of the logarithmic difference between model and observations. The combination of these two terms allows best-fitting of observations on both fast-flowing and slow-moving areas (Morlighem and others, 2010, 2013). The last term is a Tikhonov regularization term, which penalizes uncontrolled oscillations of $\alpha$ and prevents overfitting the data. $\gamma_{1}, \gamma_{2}$ and $\gamma_{\mathrm{t}}$ are non-dimensionalizing constants taken as $\gamma_{1}=300, \gamma_{2}=1.5$ and $\gamma_{\mathrm{t}}=10^{-7}$ in order to balance these three terms. The algorithm relies on an exact adjoint that includes dependency of ice viscosity into the strain rate
(Goldberg and Sergienko, 2011) for the derived gradient and quasi-Newton (limited-memory BFGS (Broyden-FletcherGoldfarb-Shanno); Nocedal, 1980) for the gradient descent.

\section{Data}

We use the datasets provided by the SeaRISE assessment (Bindschadler and others, 2013). The dataset (http:// websrv.cs.umt.edu/isis/index.php/SeaRISE_Assessment) includes mean annual surface temperature and accumulation from Ettema and others (2009), basal heat flux from Shapiro and Ritzwoller (2004) and bedrock topography, ice thickness and surface elevation from Bamber and others (2001). Observed surface velocities needed for the model initialization are from Rignot (2012). Ice front position is chosen to match the velocity datasets and is kept fixed with time. We treat the entire domain as grounded, to be consistent with the SeaRISE dataset. Large uncertainties exist in the geothermal heat flux (Greve, 2005; Rogozhina and others, 2012). We therefore adjust the geothermal flux map from Shapiro and Ritzwoller (2004) with values similar to Greve (2005) for Dye3 and GRIP. Geothermal flux values of $20 \mathrm{~mW} \mathrm{~m}^{-2}$ for the Dye 3 site and $60 \mathrm{~mW} \mathrm{~m}^{-2}$ for the GRIP site are used (Greve, 2005) and combined with the underlying geothermal heat flux map in their vicinity. We choose here to use an exponential decay as we move further from the drilling site, with an influence area of $250 \mathrm{~km}$.

For the climate scenario (see below), air temperatures and surface mass balance for the next 94 years follow the A1B scenario of the Intergovernmental Panel on Climate Change (IPCC) Fourth Assessment Report (AR4) (Pachauri and Reisinger, 2007) and are kept constant for the last 6 years of the run. Surface mass-balance anomalies compared to present-day values from Ettema and others (2009) are applied for the climate run, as described by Bindschadler and others (2013) and Nowicki and others (2013). Air temperature and surface mass balance are directly applied at the upper surface elevation.

Modeled temperatures are compared with measurements from three deep ice cores: Dye 3 (Gundestrup and Hansen, 1984; Dahl-Jensen and others, 1998); GRIP (Johnsen and others, 1995; Dahl-Jensen and others, 1998) and Greenland Ice Sheet Project 2 (GISP2) (Cuffey and others, 1995; Clow and others, 1996).

\section{Model set-up}

To run a large-scale HO model of Greenland and capture the narrow and fast-flowing ice streams while maintaining a reasonable computational cost, we rely on anisotropic mesh adaptation to limit the number of elements. The element size is optimized to minimize the interpolation error of surface velocities (Morlighem and others, 2010). The model horizontal resolution varies between $1 \mathrm{~km}$ on the fast ice streams along the coast and $25 \mathrm{~km}$ in the slow-moving regions of the interior, which results in a two-dimensional triangular mesh of $\sim 64000$ elements. The spatial resolution must be sufficiently high to allow for a good representation of the outlet glaciers but coarse enough that the model remains computationally manageable. A $1 \mathrm{~km}$ resolution gives a reasonable trade-off. The horizontal mesh is then extruded into 25 non-uniform layers between the bedrock and surface elevations. Vertical grid spacing is refined towards the bottom where temperature gradients and vertical shearing are concentrated (the layer next to the bed is half the height of the upper layer). The 3-D mesh comprises $>1500000$ 
prismatic elements. We use the arbitrary EulerianLagrangian method (Donea and Belytschko, 1992) to update the mesh at each time-step of the 100 year simulations: the horizontal mesh is fixed in time while the vertical repartition of elements varies according to the ice upper surface.

We initialize the model using the present-day geometry (ice thickness, surface elevation, ice front position). We use an inverse method to estimate the basal friction coefficient, in order to fit the present-day observed surface velocities (MacAyeal, 1993b; Morlighem and others, 2010). The thermal regime is assumed to be in steady state, and we ensure that velocities and temperatures are consistent by running a thermomechanical steady state until both fields converge: at each iteration of the inversion, we compute the ice temperature and update ice hardness accordingly, to ensure consistent ice flow and thermal regimes (Morlighem and others, 2010). The initial temperature computed is therefore based only on present-day conditions and does not include past climate history.

\section{Experiments}

We first analyze the effect of initial temperatures on the inferred basal friction for a static model. We then assess the sensitivity of the total ice volume to the initial temperature regimes for projections of 100 years, using constant presentday conditions of the atmospheric forcing. We rely on four different initial ice thermal regimes: (1) steady-state temperatures calculated from the initial velocities; (2) a linear variation from $3^{\circ} \mathrm{C}$ at the bed to $0^{\circ} \mathrm{C}$ at the surface added to the steady-state temperatures (EXP1); (3) a warm model, where the temperature varies linearly between the surface temperature and the pressure-melting point at the base (ice is therefore at the pressure-melting point everywhere at the base) (EXP2); and (4) a cold-ice model, where the temperature is equal to the surface temperature for the entire ice column (EXP3).

In order to compare the effect of the thermal regime with that of other forcings, we run two additional 100 year simulations, using steady-state temperatures: (1) a climate run following the IPCC-AR4 A1B scenario and (2) a sliding run, in which basal friction is reduced by one-third over the entire ice sheet, to simulate enhanced basal melting. The climate experiment simulates realistic changes, and the sliding experiment a commonly used scenario (e.g. GilletChaulet and others, 2012; Bindschadler and others, 2013).

\section{RESULTS}

The model initial configuration matches the ice geometry and velocity well, as expected, since it uses present-day topography and is initialized with data assimilation of observed velocities. The difference between observed and modeled velocities is $11.0 \mathrm{~m} \mathrm{a}^{-1}$ on average. Figure 1 shows the initial ice thickness (Fig. 1a) and modeled velocity (Fig. 1b), as well as the absolute difference between modeled and observed velocities (Fig. 1d). The largest differences are found along the periphery of the ice sheet, where velocities are highest (almost $1000 \mathrm{ma}^{-1}$ difference on Peterman Gletscher). Areas with high friction (Fig. 3i) are concentrated on mountainous regions, while very low friction is found under fast ice streams, as expected. Additional inversions were performed with different initial guesses of basal friction and led to similar results (not shown here), demonstrating the limited influence of the initial value.
We first compare the modeled temperatures (that were computed assuming thermal steady state) with temperature measurements along three deep ice cores (Fig. 2). The modeled steady-state profiles compare well with the measurements. GRIP and GISP2 profiles are similar, as expected, as these two ice cores are located only $28 \mathrm{~km}$ apart. For these two profiles, modeled ice temperature in the upper $2000 \mathrm{~m}$ is in good agreement with the measurements. Differences up to $5^{\circ} \mathrm{C}$ are concentrated in the lower part of the ice sheet. Differences for Dye 3 are smaller, with a maximum difference of $4^{\circ} \mathrm{C}$ at the base. Standard errors between observed and modeled temperatures are $1.3^{\circ} \mathrm{C}, 1.8^{\circ} \mathrm{C}$ and $1.9^{\circ} \mathrm{C}$ for Dye 3 , GISP2 and GRIP ice cores, respectively.

The steady-state temperatures can be compared with modeled temperatures from paleoclimate reconstructions of Aschwanden and others (2012) and Rogozhina and others (2012). The pattern of basal temperatures (Fig. 1c) is similar, with ice at the pressure-melting point over a large portion of the Greenland ice sheet and colder ice mainly along the divides and in the north.

The three different initial thermal regimes (EXP1, EXP2 and EXP3) are then used to assess the sensitivity of inferred basal friction to initial thermal regime (Fig. 3). All models are able to accurately reproduce the surface velocities, with an average misfit of 10.7, 13.5 and $11.0 \mathrm{~m} \mathrm{a}^{-1}$ for EXP1, EXP2 and EXP3, respectively. Differences between steady state and EXP1 are limited, with slightly slower basal velocities (Fig. 3e and f) and higher friction coefficients in the interior for EXP1 (Fig. 3i and j). This higher friction compensates for vertical shearing due to higher temperatures next to the base of the ice sheet. EXP2 and EXP3 initial temperatures are quite different from the steady-state temperature field so it is not surprising to see that results of the inversion are also different. EXP2 leads to significantly higher friction coefficients and lower basal velocities (Fig. $3 g$ and k), especially in the interior of the ice sheet. Results for EXP3 show the opposite, i.e. lower friction coefficient and higher basal velocities (Fig. $3 \mathrm{~h}$ and I), but the effect is more limited in this case than for EXP2. Overall, we notice that basal friction and sliding seem to be more sensitive to initial temperature conditions in the interior of the ice sheet than in the periphery.

We then perform four runs of 100 years using these different initial thermal regimes. Under constant present-day conditions and with the initial steady-state temperature, the model yields an increase in ice mass in the next 100 years of $180 \mathrm{Gta}^{-1}$, equivalent to an increase of $0.73 \%$ of the initial ice mass of the ice sheet (Fig. 4). Results of Bindschadler and others (2013) show that mass increase is a limitation common to about half of the ice-sheet models that participated in the SeaRISE experiments, the other half starting from an initial volume that differs from the presentday volume. Differences between the steady state and EXP1 are limited, with a similar mass gain $(0.73 \%$ and $0.72 \%$, respectively). EXP3 mass change is also close to the steadystate evolution, with a mass gain of $0.75 \%$. Results from EXP2 are different from the other three, with a lower mass increase of only $0.62 \%$ in 100 years. These results are further analyzed below.

Finally, we run scenarios similar to the SeaRISE initiative (Bindschadler and others, 2013; Nowicki and others, 2013) with the steady-state temperature field as initial state. Ice mass change for the climate and sliding scenarios is also presented in Figure 4 . These two scenarios respectively lead to a mass gain of $0.50 \%$ and $0.36 \%$, which is significantly 

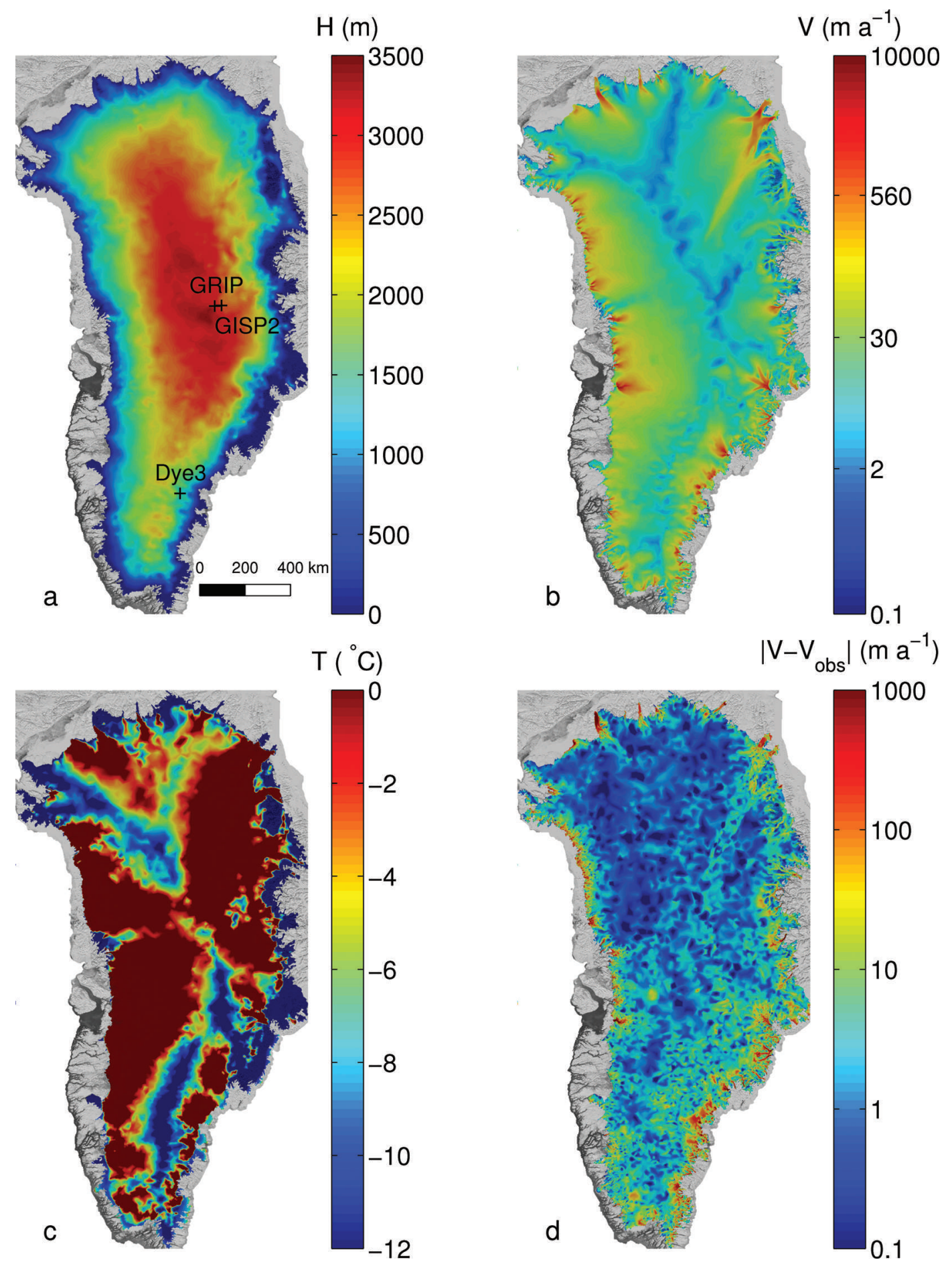

Fig. 1. Initial Greenland configuration: (a) ice thickness, $H$ (Bamber and others, 2001), (b) modeled horizontal surface velocity, $V$, (c) basal pressure-adjusted temperature, $T$, and (d) absolute misfit between observed and modeled horizontal surface velocity overlaid on a MODIS (Moderate Resolution Imaging Spectroradiometer) Mosaic of Greenland.

lower than in all the previous runs. Our 100 year simulations are therefore significantly more sensitive to the applied external forcings than the initial temperature.

\section{DISCUSSION}

Large-scale high-resolution simulations require intensive computational resources. In this study, we use a 3-D HO model, as a trade-off between first-order SSA/SIA and FS. Our model comprises 1500000 elements to capture outlet glaciers while running century-scale simulations in a reasonable amount of time (i.e. $\sim 4$ days for each run of 100 years). Previous studies (Hindmarsh, 2004; Gudmundsson, 2008; Morlighem and others, 2010) on both idealized geometries and real glaciers showed that differences between $\mathrm{HO}$ and FS exist, especially in the grounding line area (Durand and others, 2009; Morlighem and others, 2010) but remain spatially limited, so using $\mathrm{HO}$ for our simulations should not affect our conclusions.

The numerical experiments performed here show that the assumption of thermal steady state is a viable approximation for short-term simulations of the Greenland ice sheet. First, 

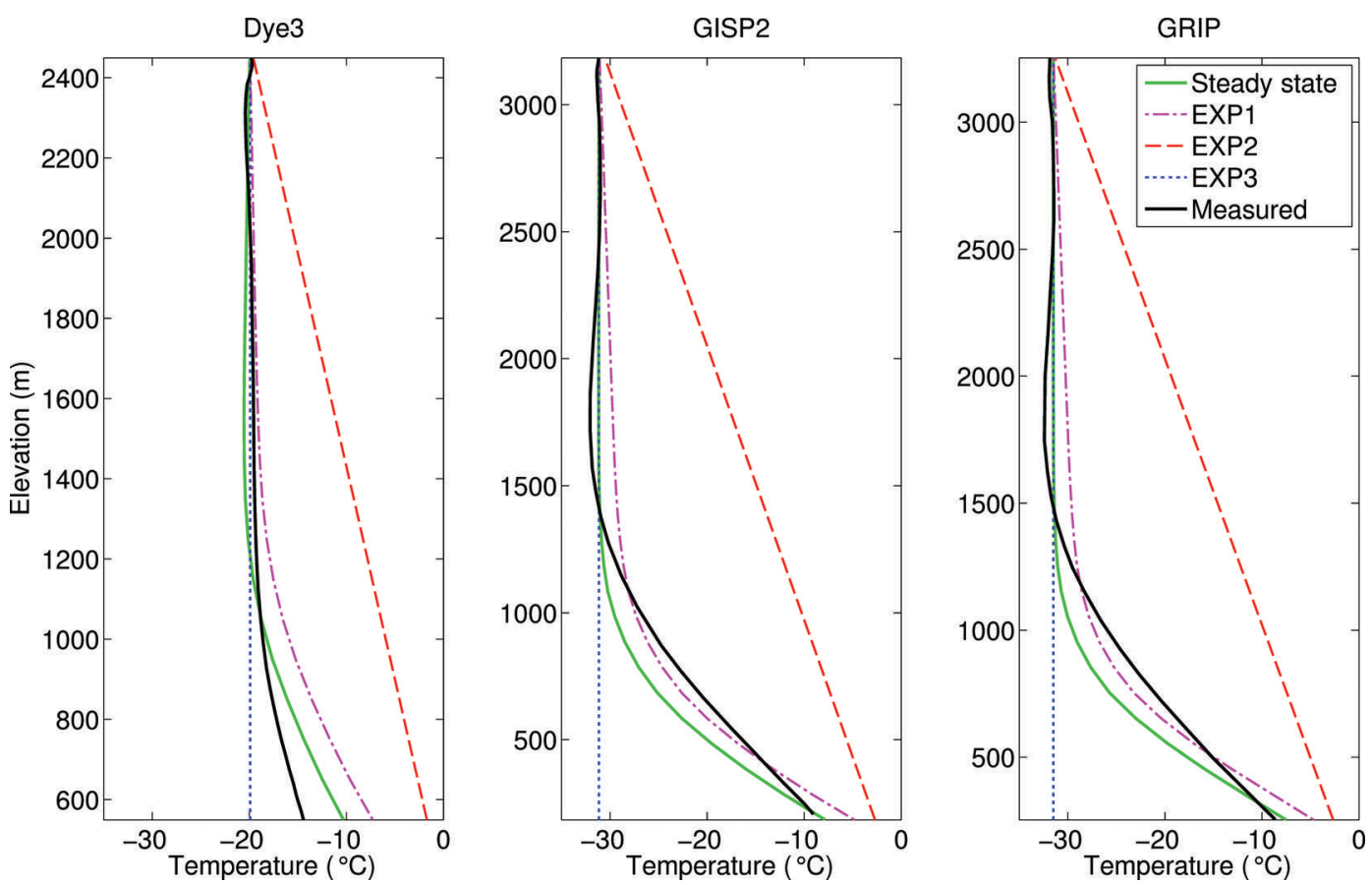

Fig. 2. Observed (black curves) and modeled steady-state (green curves) temperature profiles at Dye3, GISP2 and GRIP drilling sites. Initial temperatures for EXP1 (pink dot-dashed curves), EXP2 (red dashed curves) and EXP3 (blue dotted curves).

modeled steady-state temperatures match the observations along the three deep ice cores reasonably well. The main features of the temperature profiles (e.g. surface temperature, basal temperature, basal temperature gradient) are captured, with a standard error varying between 1.3 and $1.9^{\circ} \mathrm{C}$, even though differences with deep ice cores reach $5{ }^{\circ} \mathrm{C}$ near the glacier base. These errors correspond to an average ice rigidity difference of $3.5 \%$ for Dye 3 and $5 \%$ for GRIP and GISP. In the upper part of the ice, the modeled temperatures reach a constant value, which is not consistent with the observations. This is due to the air temperature history that is not captured here, as opposed to Greve (2005) and Rogozhina and others (2012): the temperature decrease caused by the Last Glacial Maximum is not captured by our steady-state method. Paleoclimate reconstructions, which account for temporal changes in surface conditions, yield a better agreement between modeled temperature and measurements along deep ice core (e.g. $<3^{\circ} \mathrm{C}$ in Rogozhina and others, 2012). It is important to note that these deep ice-core drillings were collected near ice divides, where conduction is dominant, and might not be representative of areas where advection is dominant. Comparisons in more dynamic areas would better inform the steady-state model's ability to capture variations, but measurements in these regions are almost non-existent.

Second, for all four temperature fields the basal drag inversions yield a good agreement between modeled and observed velocities. The temperature field affects the friction coefficient pattern, especially with the extreme cold and warm cases (EXP2 and EXP3), but the basal stress remains similar in all four cases. This result corroborates the conclusions of Schäfer and others (2012), who showed that the friction distribution of Vestfonna ice cap, Nordaustlandet/Svalbard, does not depend significantly on ice temperature. The surface velocity is optimized to fit observations and should not vary from one simulation to the next. Warmer ice deforms more easily and leads to more vertical shear; this larger vertical shear is compensated for by a lower basal velocity in order to obtain the same surface velocity. This effect is the foundation of the SIA, that is valid for most ice-sheet interiors, but does not hold for fastflowing outlet glaciers, where sliding dominates ice motion.

The pattern of inferred basal friction based on steady-state temperatures is consistent with the results of Larour and others (2012a) and Gillet-Chaulet and others (2012) for Greenland, and Joughin and others (2001) and Seroussi and others (2011) for the northeast Greenland ice stream, with motion mainly due to sliding on fast-flowing areas and differences from observations concentrated on the fastflowing outlet glaciers. These models use different approximations of FS and different temperature fields (thermal steady state for Larour and others, 2012a; an interpolation from a paleoclimate reconstruction for Gillet-Chaulet and others, 2012) and confirm that ice temperatures have little impact on the basal friction inferred from surface velocities.

Finally, the projection of the ice-sheet mass balance over the next 100 years shows an increase in mass of $\sim 0.73 \%$. This result is not consistent with the current trends that show a rapid and accelerated decrease of the Greenland ice sheet mass (e.g. Rignot and others, 2011). However, a mass increase is not unusual for ice-sheet models of the Greenland ice sheet. About half the models that participated in the Greenland SeaRISE experiments show a mass increase for the control run that keeps present-day conditions constant (Bindschadler and others, 2013), although they all use different ice-flow approximations, spatial resolutions and initialization procedures. The other models show a mass decrease but start from an initial volume that differs from the actual volume. Mass increase often happens for models initialized with inverse methods and is caused by data that have inconsistencies (Seroussi and others, 2011), incorrect position of the ice-sheet margin, mesh resolutions too coarse (Gillet-Chaulet and others, 2012) and/or missing physical processes, such as ice/ocean interaction and basal 

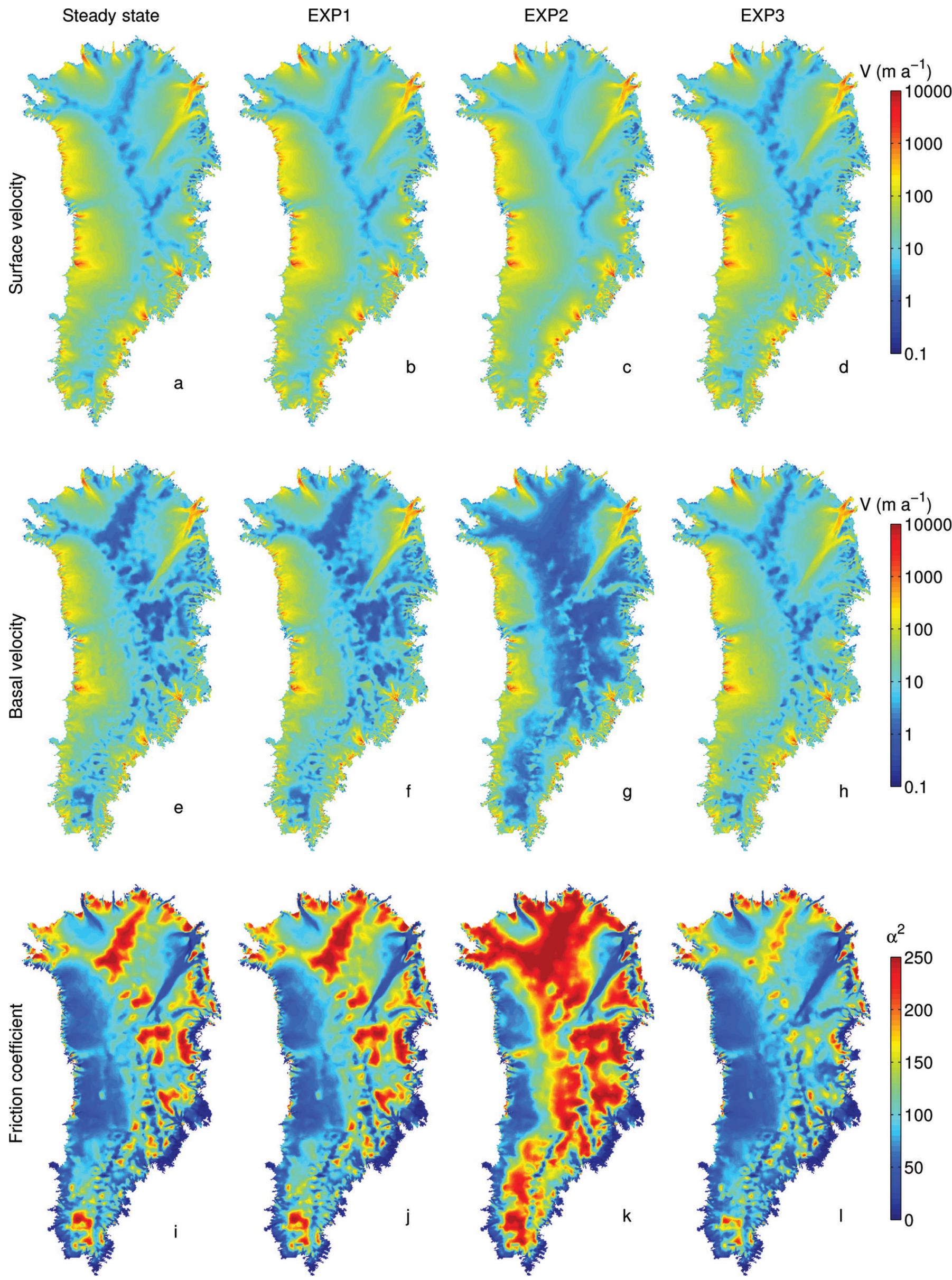

Fig. 3. (a-d) Surface velocities, (e-h) basal velocities and (i-l) friction coefficient, $\alpha^{2}$, for the four temperature profiles. First column corresponds to steady-state temperature (a, e, i), second column to EXP1 (b, f, j), third column to EXP2 (c, g, k) and fourth column to EXP3 $(d, h, l)$. 
hydrology. Models by Seddik and others (2012) and GilletChaulet and others (2012) show a volume increase of $0.81 \%$ and $0.28 \%$ in 100 years, respectively, after an initial relaxation of 100 and 50 years, respectively. Such a relaxation allows the reconciliation of inconsistent model inputs that lead to unphysical flux divergences (Seroussi and others, 2011) and limit the high rates of thickness change. However, no ice-sheet model is able to replicate the presentday configuration and evolution today. We did not use such a relaxation technique here, which could lead to slightly different initial conditions (ice thickness, initial volume, driving stress, etc.), in order to ensure that the ice-sheet response is due only to changes in the ice thermal regime.

For century-scale projections, our experiments show that the initial thermal regime has only a limited effect on the evolution of the Greenland ice sheet. Ice temperature of models that do not start with a thermal steady state see their temperatures gradually adjusted, but this is a slow process that has a limited effect for short-term simulations. Influence of geothermal heat flux will have a similar impact. Larour and others (2012b) showed that large variations of geothermal flux affected the ice rigidity by up to $5 \%$ in slow-moving areas, where basal friction and geothermal energy are the same order of magnitude. This is within the range of the initial temperature variations that we tested here. We therefore expect that uncertainties in geothermal heat flux do not significantly affect the behavior of the ice sheet for century-scale simulations. This is consistent with the results of Larour and others (2012b), who concluded that uncertainties in geothermal heat flux affect glacier mass balance by $<1 \%$. This is not the case for long interglacial runs, where temperature plays a major role in ice-sheet growth; Greve (2005) and Rogozhina and others (2012) noticed that small variations in geothermal flux led to differences in ice volume of up to $10 \%$. By contrast, changes in external forcings, such as atmospheric conditions or basal friction, lead to significant variations in ice-sheet mass over 100 years, despite the moderate forcings applied in our forcing experiments. Results from the SeaRISE experiments (Bindschadler and others, 2013) and Gillet-Chaulet and others (2012) also show the strong influence of these forcings over short timescales.

As mentioned in the previous section, mass increase is higher for EXP3 than for the steady-state experiment and lower for EXP1 and EXP2. We would expect the opposite: for identical surface velocities, depth-averaged velocities should be smaller for warmer ice, as there is more vertical shear and basal velocity from the inversion shows a lower basal velocity for EXP2 than for the steady-state case. Ice discharge is mainly controlled by fast-flowing outlet glaciers, and as motion due to vertical shear only represents a fraction of the ice velocity in these areas, ice flux is not affected. Conversely, differences between observed and modeled velocities have a stronger effect. Contrary to EXP1 and EXP3, Greenland mass evolution with EXP2 is quite different from the steady-state case. This is due to the initial velocity after inversion, which is higher than observed, especially in the eastern and southeastern part of Greenland (Fig. 5a), where the difference reaches $50 \mathrm{~m} \mathrm{a}^{-1}$ over large areas. In all other cases, the modeled velocity is usually smaller than the measurements (e.g. EXP3 in Fig. 5b: the difference between observed and modeled velocities is $\sim 0 \mathrm{ma}^{-1}$ in those same areas). This higher velocity leads to a discharge at the ice front that is $10 \%$

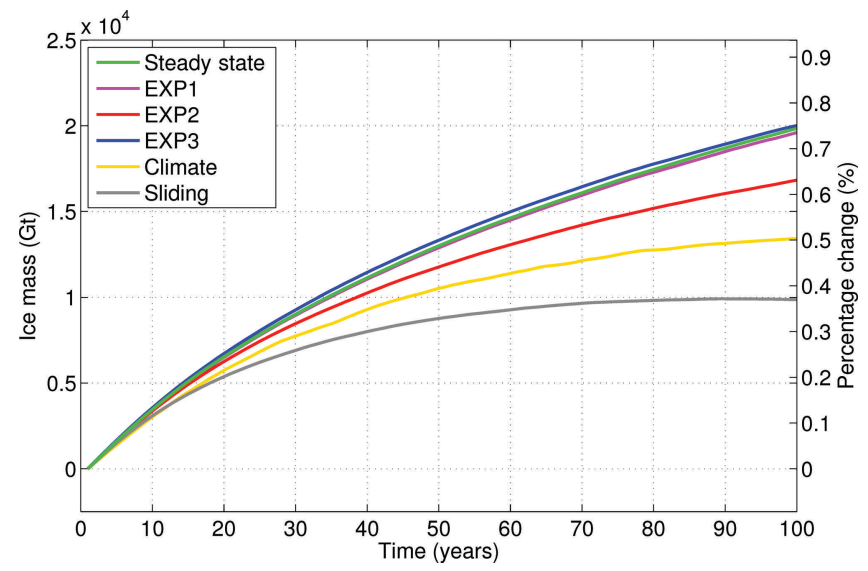

Fig. 4. Simulated ice mass change of the Greenland ice sheet (in Gt and $\%$ ) for 100 year simulations with different scenarios: constant climate with steady-state temperature (green), EXP1 temperature (violet), EXP2 temperature (red), EXP3 temperature (dark blue), AR4 atmospheric conditions (yellow) and increased basal lubrication (gray).

higher for EXP2 than for the steady state and EXP1 and EXP3 cases. The inversion for EXP2 did not converge as well as the others, even though the absolute misfit is only slightly higher for this experiment than for the others $\left(13.5 \mathrm{~m} \mathrm{a}^{-1}\right.$ for EXP2 vs 10.7 and $11.0 \mathrm{~m} \mathrm{a}^{-1}$ for EXP1 and EXP3). This suggests that the model is highly sensitive to the initial modeled velocity and that this parameter has a significantly larger impact on simulations than changes in initial temperatures.

The basal friction law employed here is not temperaturedependent, and only the effective pressure changes as the ice-sheet geometry evolves. Projections of the Greenland ice sheet evolution could be more sensitive to the initial temperature field if a temperature-dependent friction law were used, as nonlinear effects could develop. However, most of the ice sheet is already at the pressure-melting point (Fig. 1c), which limits the impact of such a law, and our conclusions should not be significantly affected. A basal hydrological model that models effective pressure and water content (de Fleurian, 2013) is under development and will improve this aspect in the future.

Realistic modeling of the ice thermal regime remains a major objective and more in situ measurements need to be acquired to calibrate and validate models. There are few temperature measurements available in fast-flowing areas, and uncertainties associated with the geothermal heat flux, which is a key control on the thermal regime, remain large. Our results indicate that variations of $<5^{\circ} \mathrm{C}$ in parts of the ice sheet in the initial temperature field have a limited effect on both initializations with data assimilation and ice-sheet evolution for short-term simulations of large-scale models. Other factors and parameters are of greater importance: an accurate representation of small outlet glaciers is necessary to capture the ice discharge; a realistic description of the ice-sheet present-day configuration with improved bedrock topography data is needed to reduce uncertainties, as well as better constrain mass flux and unknown parameters (Seroussi and others, 2011; Gillet-Chaulet and others, 2012). These aspects are more limiting for ice-sheet numerical modeling and affect sea-level rise projections at the continental scale more significantly than small variations in the ice thermal regime. 
EXP2

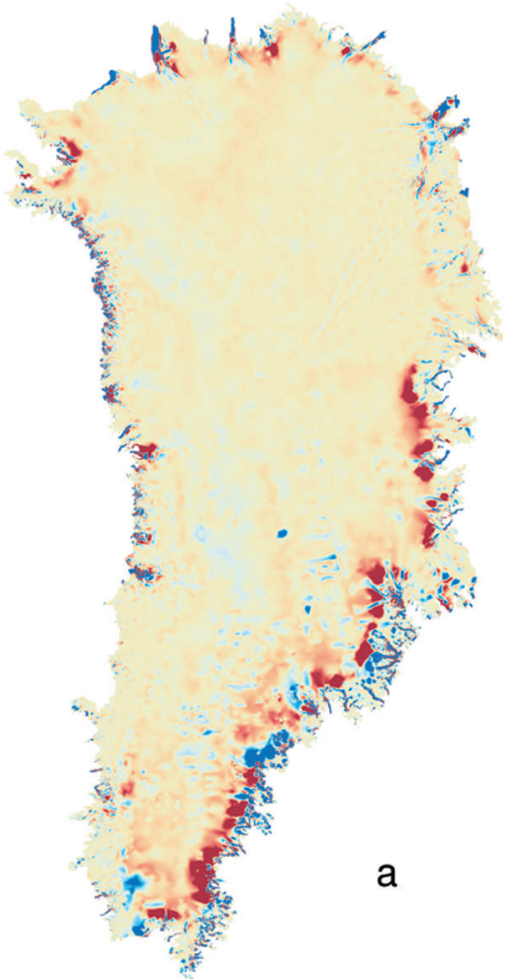

EXP3

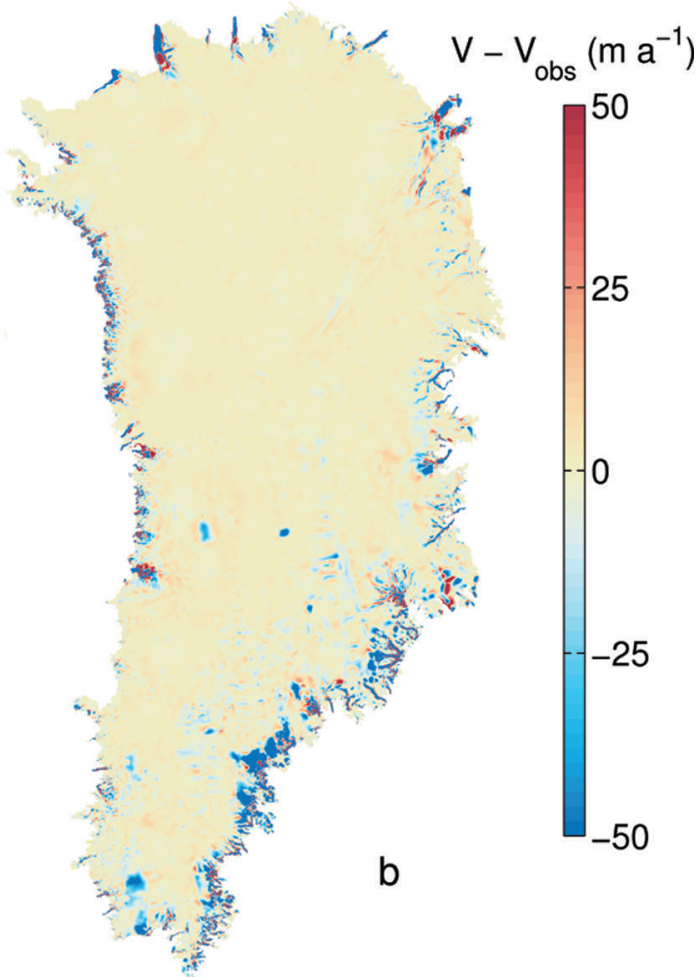

Fig. 5. Modeled minus observed velocities for (a) EXP2 and (b) EXP3. Modeled velocities are higher than observations in red areas and lower in blue areas.

\section{CONCLUSIONS}

In this study, we have presented simulations performed with a 3-D thermomechanical $\mathrm{HO}$ model of the Greenland ice sheet. Anisotropic mesh adaptation and data assimilation allow the numerical model to capture outlet glaciers with better accuracy and to match the present-day conditions in a realistic manner. We show that modeled temperatures, assuming an ice sheet in thermal steady state, are in agreement with in situ measurements along three deep ice-core profiles. The impact on ice rigidity is $5 \%$ or less, and such changes do not have a significant influence on basal friction inversion and ice-sheet evolution for centuryscale projections. The ice-sheet model is far more sensitive to changes in external forcings, namely basal sliding and atmospheric conditions, than its initial temperature. Using a steady-state approach combined with present-day conditions to compute the ice thermal regime is a viable alternative to spin-up when looking at short-term simulations of the Greenland ice sheet at the continental scale.

\section{ACKNOWLEDGEMENTS}

This work was performed at the Jet Propulsion Laboratory (JPL), California Institute of Technology, and University of California, Irvine, under a contract with the NASA Cryospheric Sciences Program. H.S. was supported by an appointment to the NASA postdoctoral program at the JPL, administered by Oak Ridge Associated Universities through a contract with NASA. A.K. was supported by a grant from NASA's Cryospheric Sciences Program. We thank the scientific editor, R. Greve, as well as A. Aschwanden and an anonymous reviewer for comments which helped improve the clarity of the manuscript.

\section{REFERENCES}

Alley RB and 10 others (1993) Abrupt increase in Greenland snow accumulation at the end of the Younger Dryas event. Nature, 362(6420), 527-529

Applegate PJ, Kirchner N, Stone EJ, Keller K and Greve R (2012) An assessment of key model parametric uncertainties in projections of Greenland Ice Sheet behavior. Cryosphere, 6(3), 589-606 (doi: 10.5194/tc-6-589-2012)

Aschwanden A, Aðalsgeirsdóttir G and Khroulev C (2012a) Hindcasting to measure ice sheet model sensitivity to initial states. Cryos. Discuss., 6(6), 5069-5094 (doi: 10.5194/tcd-65069-2012)

Aschwanden A, Bueler E, Khroulev C and Blatter H (2012b) An enthalpy formulation for glaciers and ice sheets. J. Glaciol., 58(209), 441-457 (doi: 10.3189/2012JoG11J088)

Bamber JL, Layberry RL and Gogineni SP (2001) A new ice thickness and bed data set for the Greenland ice sheet. 1. Measurement, data reduction, and errors. J. Geophys. Res., 106(D24), 33 773-33 780 (doi: 10.1029/2001JD900054)

Benn DI, Warren CW and Mottram RH (2007) Calving processes and the dynamics of calving glaciers. Earth-Sci. Rev., 82(3-4), 143-179 (doi: 10.1016/j.earscirev.2007.02.002)

Bindschadler RA and 27 others (2013) Ice-sheet model sensitivities to environmental forcing and their use in projecting future sea level (the SeaRISE project). J. Glaciol., 59(214), 195-224 (doi: 10.3189/2013JoG12J125)

Blatter H (1995) Velocity and stress fields in grounded glaciers: a simple algorithm for including deviatoric stress gradients. J. Glaciol., 41(138), 333-344

Brooks AN and Hughes TJR (1982) Streamline upwind/PetrovGalerkin formulations for convection dominated flows with particular emphasis on the incompressible Navier-Stokes equations. Comput. Meth. Appl. Mech. Eng., 32(1-3), 199-259 (doi: 10.1016/0045-7825(82)90071-8)

Bueler E and Brown J (2009) Shallow shelf approximation as a 'sliding law' in a thermomechanically coupled ice sheet 
model. J. Geophys. Res., 114(F3), F03008 (doi: 10.1029/ 2008JF001179)

Clow GD, Saltus RW and Waddington ED (1996) A new highprecision borehole-temperature logging system used at GISP2, Greenland, and Taylor Dome, Antarctica. J. Glaciol., 42(142), 576-584

Cuffey KM and Paterson WSB (2010) The physics of glaciers, 4th edn. Butterworth-Heinemann, Oxford

Cuffey KM, Clow GD, Alley RB, Stuiver M, Waddington ED and Saltus RW (1995) Large Arctic temperature change at the Wisconsin-Holocene glacial transition. Science, 270(5235), 455-458 (doi: 10.1126/science.270.5235.455)

Dahl-Jensen D and 6 others (1998) Past temperatures directly from the Greenland ice sheet. Science, 282(5387), 268-271 (doi: 10.1126/science.282.5387.268)

Dansgaard W and 10 others (1993) Evidence for general instability of past climate from a $250 \mathrm{kyr}$ ice-core record. Nature, 364(6434), 218-220 (doi: 10.1038/364218a0)

De Fleurian B and 6 others (2013) A subglacial hydrological model dedicated to glacier sliding. Cryos. Discuss., 7(4), 3449-3496 (doi: 10.5194/tcd-7-3449-2013)

DeConto RM and Pollard D (2003) Rapid Cenozoic glaciation of Antarctica induced by declining atmospheric $\mathrm{CO}_{2}$. Nature, 421(6920), 245-248 (doi: 10.1038/nature01290)

Donea J and Belytschko T (1992) Advances in computational mechanics. Nucl. Eng. Des., 134(1), 1-22 (doi: 10.1016/00295493(92)90004-F)

Durand G, Gagliardini O, Zwinger T, Le Meur E and Hindmarsh RCA (2009) Full Stokes modeling of marine ice sheets: influence of the grid size. Ann. Glaciol., 50(52), 109-114 (doi: 10.3189/ 172756409789624283)

Ettema J and 6 others (2009) Higher surface mass balance of the Greenland ice sheet revealed by high-resolution climate modelling. Geophys. Res. Lett., 36(12), L12501 (doi: 10.1029/ 2009GL038110)

Gillet-Chaulet F and 8 others (2012) Greenland Ice Sheet contribution to sea-level rise from a new-generation ice-sheet model. Cryosphere, 6(4), 1561-1576 (doi: 10.5194/tc-6-1561-2012)

Glen JW (1955) The creep of polycrystalline ice. Proc. R. Soc. London, Ser. A, 228(1175), 519-538 (doi: 10.1098/rspa. 1955.0066)

Goldberg DN and Sergienko OV (2011) Data assimilation using a hybrid ice flow model. Cryosphere, 5(2), 315-327 (doi: 10.5194/tc-5-315-2011)

Greenland Ice-Core Project (GRIP) members (1993) Climate instability during the last interglacial period recorded in the GRIP ice core. Nature, 364(6434), 203-207 (doi: 10.1038/364203a0)

Greve R (1997a) A continuum-mechanical formulation for shallow polythermal ice sheets. Philos. Trans. R. Soc. London, Ser. A, 355(1726), 921-974 (doi: 10.1098/rsta.1997.0050 )

Greve R (1997b) Application of a polythermal three-dimensional ice sheet model to the Greenland ice sheet: response to steadystate and transient climate scenarios. J. Climate, 10(5), 901-918 (doi: 10.1175/1520-0442(1997)010<0901:AOAPTD>2.0.CO;2)

Greve R (2005) Relation of measured basal temperatures and the spatial distribution of the geothermal heat flux for the Greenland ice sheet. Ann. Glaciol., 42(1), 424-432 (doi: 10.3189/ 172756405781812510)

Greve R, Saito F and Abe-Ouchi A (2011) Initial results of the SeaRISE numerical experiments with the models SICOPOLIS and ICIES for the Greenland ice sheet. Ann. Glaciol., 52(58), 23-30 (doi: 10.3189/172756411797252068)

Gudmundsson GH (2008) Analytical solutions for the surface response to small amplitude perturbations in boundary data in the shallow-ice-stream approximation. Cryosphere, 2(2), 77-93 (doi: 10.5194/tc-2-77-2008)

Gundestrup NS and Hansen BL (1984) Bore-hole survey at Dye 3, south Greenland. J. Glaciol., 30(106), 282-288

Hindmarsh RCA (2004) A numerical comparison of approximations to the Stokes equations used in ice sheet and glacier modeling. J. Geophys. Res., 109(F1), F01012 (doi: 10.1029/ 2003JF000065)

Holland DM, Thomas $\mathrm{RH}$, de Young B, Ribergaard $\mathrm{MH}$ and Lyberth B (2008) Acceleration of Jakobshavn Isbræ triggered by warm subsurface ocean waters. Nature Geosci., 1(10), 659-664 (doi: 10.1038/ngeo316)

Howat IM, Joughin IR and Scambos TA (2007) Rapid changes in ice discharge from Greenland outlet glaciers. Science, 315(5818), 1559-1561 (doi: 10.1126/science.1138478)

Hutter K (1982) Dynamics of glaciers and large ice masses. Annu. Rev. Fluid Mech., 14, 87-130 (doi: 10.1146/annurev.fl.14. 010182.000511)

Johnsen SJ, Dahl-Jensen D, Dansgaard W and Gundestrup NS (1995) Greenland paleotemperatures derived from GRIP borehole temperature and ice core isotope profiles. Tellus, $47 \mathrm{~B}(5)$, 624-629

Joughin I, Fahnestock M, MacAyeal D, Bamber JL and Gogineni P (2001) Observation and analysis of ice flow in the largest Greenland ice stream. J. Geophys. Res., 106(D24), 34021-34034 (doi: 10.1029/2001JD900087)

Larour E, Seroussi H, Morlighem M and Rignot E (2012a) Continental scale, high order, high spatial resolution, ice sheet modeling using the Ice Sheet System Model (ISSM). J. Geophys. Res., 117(F1), F01022 (doi: 10.1029/2011JF002140)

Larour E, Morlighem M, Seroussi H, Schiermeier J and Rignot E (2012b) Ice flow sensitivity to geothermal heat flux of Pine Island Glacier, Antarctica. J. Geophys. Res., 117(F4), F04023 (doi: 10.1029/2012JF002371)

MacAyeal DR (1989) Large-scale ice flow over a viscous basal sediment: theory and application to Ice Stream B, Antarctica. J. Geophys. Res., 94(B4), 4071-4087 (doi: 10.1029/ JB094iB04p04071)

MacAyeal DR (1993a) A tutorial on the use of control methods in ice-sheet modeling. J. Glaciol., 39(131), 91-98

MacAyeal DR (1993b) Binge/purge oscillations of the Laurentide ice sheet as a cause of the North Atlantic's Heinrich events. Paleoceanography, 8(6), 775-784 (doi: 10.1029/93PA02200)

McFadden EM, Howat IM, Joughin I, Smith BE and Ahn Y (2011) Changes in the dynamics of marine terminating outlet glaciers in west Greenland (2000-2009). J. Geophys. Res., 116(F2), F02022 (doi: 10.1029/2010JF001757)

Meese DA and 8 others (1994) The accumulation record from the GISP2 core as an indicator of climate change throughout the Holocene. Science, 266(5191), 1680-1682 (doi: 10.1126/ science.266.5191.1680)

Moon T, Joughin I, Smith B and Howat I (2012) 21st-century evolution of Greenland outlet glacier velocities. Science, 336(6081), 576-578 (doi: 10.1126/science.1219985)

Morlighem M, Rignot E, Seroussi H, Larour E, Ben Dhia $H$ and Aubry D (2010) Spatial patterns of basal drag inferred using control methods from a full-Stokes and simpler models for Pine Island Glacier, West Antarctica. Geophys. Res. Lett., 37(14), L14502 (doi: 10.1029/2010GL043853)

Morlighem M, Seroussi H, Larour E and Rignot E (2013) Inversion of basal friction in Antarctica using exact and incomplete adjoints of a higher-order model. J. Geophys. Res., 118(2) (doi: 10.1002/ jgrf.20125)

Nocedal J (1980) Updating quasi-Newton matrices with limited storage. Math. Comput., 35(151), 773-782 (doi: 10.1090/ S0025-5718-1980-0572855-7)

North Greenland Ice Core Project (NorthGRIP) members (2004) High-resolution record of Northern Hemisphere climate extending into the last interglacial period. Nature, 431 (7005), 147-151 (doi: 10.1038/nature02805)

Nowicki S and 30 others (2013) Insights into spatial sensitivities of ice mass response to environmental change from the SeaRISE ice sheet modeling project I: Antarctica. J. Geophys. Res., 118(F2), 1002-1024 (doi: 10.1002/jgrf.20081)

Pachauri RK and Reisinger A eds. (2007) Climate change 2007: Synthesis Report. Contribution of Working Groups I, II and III to 
the Fourth Assessment Report of the Intergovernmental Panel on Climate Change. Intergovernmental Panel on Climate Change, Geneva

Pattyn F (2003) A new three-dimensional higher-order thermomechanical ice-sheet model: basic sensitivity, ice stream development, and ice flow across subglacial lakes. J. Geophys. Res., 108(B8), 2382 (doi: 10.1029/2002JB002329)

Phillips T, Rajaram H and Steffen K (2010) Cryo-hydrologic warming: a potential mechanism for rapid thermal response of ice sheets. Geophys. Res. Lett., 37(20), L20503 (doi: 10.1029/ 2010GL044397)

Pollard D and DeConto RM (2009) Modelling West Antarctic ice sheet growth and collapse through the past five million years. Nature, 458(7236), 329-332 (doi: 10.1038/nature07809)

Price SF, Payne AJ, Howat IM and Smith BE (2011) Committed sealevel rise for the next century from Greenland ice sheet dynamics during the past decade. Proc. Natl Acad. Sci. USA (PNAS), 108(22), 8978-8983 (doi: 10.1073/pnas.1017313108)

Rignot E (2012) Ice flow in Greenland for the International Polar Year 2008-2009. Geophys. Res. Lett., 39(11), L11501 (doi: 10.1029/2012GL051634)

Rignot E, Velicogna I, Van den Broeke MR, Monaghan A and Lenaerts J (2011) Acceleration of the contribution of the Greenland and Antarctic ice sheets to sea level rise. Geophys. Res. Lett., 38(5), L05503 (doi: 10.1029/2011GL046583)

Ritz C, Rommelaere V and Dumas C (2001) Modeling the evolution of Antarctic ice sheet over the last 420000 years: implications for altitude changes in the Vostok region. J. Geophys. Res., 106(D23), 31 943-31964 (doi: 10.1029/2001JD900232)

Rogozhina I and 6 others (2012) Effects of uncertainties in the geothermal heat flux distribution on the Greenland Ice Sheet: an assessment of existing heat flow models. J. Geophys. Res., 117(F2), F02025 (doi: 10.1029/2011JF002098)

Schäfer M and 8 others (2012) Sensitivity of basal conditions in an inverse model: Vestfonna ice cap, Nordaustlandet/Svalbard. Cryosphere, 6(4), 771-783 (doi: 10.5194/tc-6-771-2012)

Schoof C (2010) Ice-sheet acceleration driven by melt supply variability. Nature, 468(7325), 803-806 (doi: 10.1038/ nature09618)

Seddik H, Greve R, Zwinger T, Gillet-Chaulet F and Gagliardini O (2012) Simulations of the Greenland ice sheet 100 years into the future with the full Stokes model Elmer/lce. J. Glaciol., 58(209), 427-440 (doi: 10.3189/2012JoG11J177)

Seroussi $\mathrm{H}$ and 6 others (2011) Ice flux divergence anomalies on 79north Glacier, Greenland. Geophys. Res. Lett., 38(9), L09501 (doi: 10.1029/2011GL047338)

Shapiro NM and Ritzwoller MH (2004) Inferring surface heat flux distribution guided by a global seismic model: particular application to Antarctica. Earth Planet. Sci. Lett., 223(1-2), 213-224 (doi: 10.1016/j.epsl.2004.04.011)

Velicogna I (2009) Increasing rates of ice mass loss from the Greenland and Antarctic ice sheets revealed by GRACE. Geophys. Res. Lett., 36(19), L19503 (doi: 10.1029/ 2009GL040222)

MS received 19 March 2013 and accepted in revised form 23 August 2013 